\title{
Methodical Strategies In Reading English Texts
}

\begin{tabular}{l} 
Tyumen Industrial University, Volodarskogo Str, 38; Tyumen \\
ARTICLE INFORMATION \\
\hline Original Research Paper \\
Received Feb. 2018 \\
Accepted Apr. 2018 \\
Keywords: \\
Formation \\
Process \\
communicative foreign language \\
competence \\
reading
\end{tabular}

Aygul Z. Ibatova

\begin{abstract}
Foreign language as one of the means of communication occupies a special place in the system of modern higher education. The article deals with the problem of communicative foreign competence formation among students of technical specialties. The author determines the teaching of a foreign language as a special kind of speech activity, based on a clearly organized system of educational speech actions. In this study, this system is presented in the form of teaching English texts reading, which requires the use of special speech material and an exercise system for performing this type of activity. The author presented the system of exercises with the purpose of forming of students' communicative competence.
\end{abstract}

\section{Introduction}

At present, the system of higher education in Russia is undergoing significant changes. This also applies to the teaching of foreign languages in technical universities.

Many changes are quite obvious, and despite the fact that the reaction to them is far from always unambiguous, as they are it stays the subject of open discussions and disputes. Such changes include the introduction of a point-rating system for assessing students' knowledge, which, in our opinion, cannot be objective, the introduction of distance learning forms, which is not an effective form of work for teachers of foreign languages, in our opinion, etc.

Such changes occur sometimes imperceptibly, that even teachers do not have time to prepare educational and methodological materials, textbooks do not have time to be published in accordance with the new requirements of the state standard, i.e. the formation of all competences in foreign-language education is impossible. This applies to the teaching of a foreign language and the preservation of its specifics in a technical university.

Introducing new educational standards, teachers do not always understand the role and purpose of the university, since the level of freshmen should be correlated with the level of graduates of the profile school. We will not consider the whole range of problems, but we will consider the teaching of a foreign language as a process, the basic and specific principles of instruction that are characteristic for the training of students in technical specialties.

Since language is a means of communication that allows people to interact with each other, to influence each other in the natural conditions of social life, then learning a foreign language should be viewed from the position of learning communication.

In higher education, the goal of education is determined by the program - the state document, which is 
compulsory for each teacher. It provides specific guidance on the subject "Foreign Language" on the final results and intermediate in terms of years of study. According to the program of students' training in the specialty "Oil and gas business". The aim of the training is to achieve linguistic and communicative competence sufficient for further training activities, to study foreign experience in the oil and gas field, and to conduct business contacts at the elementary level. Along with the practical goal, the foreign language course sets educational and educational goals. Achieving these goals means broadening the outlook of students, raising the level of their general culture and education, as well as a culture of thinking, communication and speech, and is manifested in the willingness of specialists to promote the establishment of intercultural, professional and scientific ties (Kalyanova, 2016)

We see that the main goal is the formation of communicative competence. Consideration of the process, the definition of the essence of the formation of communicative competence and is the purpose of our study.

\section{Methodology}

The methodological basis of the research is a textual-dialogical approach (SV Belova, 2006, Serikov, 2008), stimulating aspiration, motivation for a dialogical perception of the subject, for personal and professional development. The text should be regarded as an integrative element of education, one of the most important goals of which is to help students gain some kind of personal experience, form the basic skills of communication in a foreign language.

The theoretical basis of this study is the theory of modular learning technologies (Konysheva, 2005). All the training material is presented in the form of modules - cycles. And we also used methods of analysis, synthesis of methodological and pedagogical literature.

\section{Results}

In the philosophical encyclopedic dictionary, this concept is defined as the formation, the category of dialectics, which means the process of the formation of any material or ideal object. Any formation presupposes the transition of possibility into reality in the process of development (Il'ichev, 1983). That is, the concept of "formation" is described in the context of the concepts of "becoming" and "development."

When interpreting the notion of "formation" the same categories operate, and psychologists define both the formation of the personality of a specialist and the personality of the student as a process of development, the formation of individuality and the process of acquiring professionally important knowledge, skills and qualities (Dyachenko et al, 1998).

In pedagogical literature, "formation" has a value: the process of development and formation of personality under the influence of external influences of upbringing (Kodzhaspirova, 2005); the process of its development as a social individual as a result of socialization and upbringing (Petrovsky, 1984).

Therefore, using the above-mentioned concepts, we define the formation of communicative competence in a foreign language as an integral pedagogical process based on the interaction of the teacher and students of technical specialties and aimed at mastering the students with a complex of knowledge, skills, and the 
formation of motives necessary for the effective implementation of the activity of communication in a foreign language.

Consider the essence and structure of the process of forming communicative competence in a foreign language. Essence is the meaning of communication, internal relations that determine the main features and trends in the development of any phenomenon (Gubsky, 2006). Therefore, in the process of formation of communicative competence, a process takes place in which, on the basis of mastering the knowledge, skills and skills necessary for the effective implementation of communication in a foreign language, the external objective requirements of society, namely, the requirements of the Federal State Standard of Higher Education become internal, (internal motives, motivation to study a foreign language for personal growth in the professional sphere, personal meaning.

Any pedagogical process, the process of formation of communicative competence in particular, requires guidelines. In the field of teaching foreign languages to students of technical specialties, we distinguish the principles of education, and they serve as the main guidelines for training. In the framework of our study, we will consider only a few principles. Each principle represents the basis for constructing the structure and learning that the objectives of the study. All principles are interrelated, since they operate with complementary categories and, while expanding the process of forming the communicative competence of students in a foreign language in various hypostases, complement each other.

Like any activity, the process of forming communicative competence in a foreign language assumes the existence of results. Considering the definition of the goal as "one of the elements of behavior, conscious activity characterized by an anticipation in the mind, thinking of the result of activity and ways, ways of achieving it" (Kozhaspirova, 2005; Serikov, 2008), we can state that the goal exists as "the image of the desired future" , the project-program of activities, is the main guide of human activity, the process, determines the way and nature of actions, predicts the state of reality and the concentration of the will to achieve it.

Considering the above, we note that the goal of the process is to develop the ability of students to communicate in a foreign language in the professional sphere.

In accordance with the purpose the following tasks of the process of forming this competence are put forward:

- providing students with linguistic, sociolinguistic, professional-communicative knowledge;

- development of linguistic, sociolinguistic, professional and communicative skills necessary for the effective application of the acquired knowledge in the implementation of professionally-oriented communication in a foreign language;

- creating conditions for the development of positive motivation, interest, necessary for the successful performance of this activity (Ibatova, 2017).

In order to achieve the goal and realize the tasks set, it is necessary to choose the right forms of organization of classes, methods of teaching, etc. 
Methodological support is important for the implementation of an effective pedagogical process.

Consider one of the important aspects of teaching foreign languages in a technical college - reading. Reading is a motivated, receptive, mediated kind of speech activity, proceeding in the internal plan, aimed at extracting information from a written fixed text, proceeding on the basis of visual perception processes of arbitrary shortterm memory and transcoding information. The very process of reading, which involves analysis, synthesis, generalization, inference and forecasting, has a significant educational and educational role.

Reading is both a goal and a means of teaching a foreign language, determine the methodological organization of all work. Reading the teaching texts, the student performs educational speech activity.

What is meant by the learning action of reading? It is a single act of reading a text or part of it for a specific task. For example, you need to read the text and find certain grammatical phenomena or read the text and divide it into semantic parts, etc. A feature of teaching students to read the specialty "Oil and Gas Business" is the construction of all tasks on the speech material from the field of professional activity contained in the training texts that is, functioning in the system of professional speech of oil engineers.

Let's consider the methodical organization of teaching of reading foreign language texts in English on practical for students' specialty "Oil and gas business" in the Tyumen Industrial University with the purpose of forming a communicative competence. The means of forming this competence is such a form of work as reading. The process of reading is divided into several modules (cycles).

The first cycle of classes. The main task of teaching reading in the first cycle is to show the way, following which the student will be able to understand the content of any text being studied. The performance of each speech task is one of the steps of this path and is connected with reading the text from a certain angle. The teacher should pay attention to the fact that educational speech tasks are given in expanded form only to the first text of the cycle. This means that the task includes two actions, and each of them, in turn, is divided into two operations. In the tasks for the second text, there are no fractional operations. For the third text, only general tasks are assigned, in which the basic techniques for working on the text are highlighted. When starting to work on texts, students, as a rule, should listen to an exemplary reading of the teacher or a sound recording, after which, when performing tasks, they read the texts only to themselves. Tasks for correct reading aloud are performed only after the content of the text is understood. From cycle to cycle, the reading speed should increase.

The second cycle of lessons. If in the first cycle of studies all tasks had approximately the same specific gravity, then in this and the following cycles, the types of assignments that are directly related to the information under study become more important. Therefore, the first three tasks appear to be leading, intended to familiarize themselves with the general content of the text. The success of the initial acquaintance depends to a large extent on the vocabulary of the trainee, as well as on his ability to quickly analyze the vocabulary, guess the meaning of the words in context, etc. For this purpose, in carrying out these tasks, the teacher should 
stop on the methods of determining the context meaning of words and word combinations, on the role of wordformation attributes, etc. Tasks of this type are repeated in subsequent cycles, so students, systematically exercising in this kind of work, get the opportunity in the final sc To achieve a rapid coverage of the general content of the text without special analysis of the vocabulary.

The third cycle of lessons. For the teaching of reading, the organization of the educational material discussed above is basically preserved. The leading role is played by tasks aimed at analyzing the grammatical structure of the text: groups of words, sentences, paragraphs, etc. Consider the most important grammatical indices necessary for understanding the connection of various structural units of the text, and also reveal the role of analysis in eliminating difficulties in understanding the content. Depending on the degree of preparedness of students, the teacher can increase or decrease the volume of grammatical phenomena subject to analysis, remembering that this type of educational work is not an end in itself, but one of understanding the content of the text.

The fourth cycle of lessons. The training material of the fourth cycle, which completes the first section, should ensure the fulfillment of the tasks for the formation of skills and abilities. The student should acquire the ability to quickly understand the general content of the reading, as well as analyze language phenomena in order to fully extract textual information. The teacher should show that the lexico-grammatical analysis is only one of the ways of studying the text, helping to disclose its semantic content. The training should allow the student without a long analysis and with a minimum use of the dictionary to accurately understand any text that is equal in difficulty studied and containing about $3-4 \%$ of the new vocabulary. At the same time the volume of the text is approximately 800-900 printed symbols, and the time allocated for reading should not exceed 3-4 minutes. The fulfillment of these requirements is one of the necessary conditions for the further development of more complex reading skills and abilities.

The fifth cycle of classes. One of the main directions in the teaching of introductory reading is the development of the ability to "grasp" the basic meaning of the text quite quickly. It consists of a certain speed of reading; reliance on known elements, understanding the connection between parts of the text, etc., which allows you to see the text as a whole. In this period of study, the task is to gradually master the students the basic elements of familiarization reading, when the text is reread two or three times in order to more fully elucidate the semantic relationships available in the text. An increase in the reading speed and volume of the material being studied is provided in subsequent cycles. To improve the mastery of students with linguistic material, it is advisable, after completing the work on the three texts of the cycle, to generalize the information received, suggesting a general plan, setting out the contents of the reading in the form of a retelling, and so on.

The sixth cycle of lessons. In-depth reading is a synthesis of complex skills and abilities that enable you to overcome language difficulties accurately understand the content and get the information contained in the text. In some cases, it is necessary to disclose a "deep" meaning (subtext), which the author wanted to convey to the reader. The tasks of this cycle are enlarged and arranged in the order corresponding to the path of 
formation of the above skills. Perhaps, in a number of cases, there is a need to dismember certain tasks for smaller actions and operations or to introduce new actions - all this the teacher decides, depending on the level of the students' preparation. The main task is that the student himself could determine what prevents him from understanding the content of the text, was able to cope independently with these difficulties, resorting to the help of the teacher only in individual cases. The goal will be achieved if the student can fully extract the text information.

The seventh cycle of classes. It is known that the transfer of information received during reading requires mastering special techniques that need to be mastered even in their native language. When teaching students annotation and abstracting in a foreign language, an additional task arises - to teach them to convey the meaning of the reading directly in English, bypassing the preparation in their native language. To achieve this goal, most of the typical speech tasks of the cycle are subordinated. Students preliminarily study the content of the text, and then in the classroom, under the guidance of the teacher, they perform special tasks on annotation and abstracting, for example, compose an annotation and abstract plan, highlight the necessary speech material in the text, etc. When teaching the elements of the translation, the teacher must show the difference in use native language as a means of comprehending the content of the read (training translation), and as a means of conveying the content of the text in the form of an adequate translation. In the future, it is advisable to give each student an individual assignment for translation and abstracting. The audience can be consulted on these tasks and discussed collectively in German the work performed. Thus, oral speech will become an increasingly effective means of reading teaching.

We give examples of exercises of one of the cycles.

Task one. Read the text for the purpose of initial acquaintance.

1. Read the general content of the text.

a) Read the questions to the text:

b) Give brief answers in Russian to the questions above.

2. Give the main content of the text in Russian.

a) Say that the text refers to the study of the structure of matter.

b) Outline the main content of the text in 3-4 sentences in Russian.

Task two. Determine the meaning of words and phrases from the text.

I. Set the lexical meaning of the words.

a) Refine the meaning of the words, guided by the content of the text .... 
b) Name the following words for equivalents in Russian ....

2) Set the meaning of the word combinations.

a) Find in the text the following phrases ....

b) Write the equivalents of these phrases in Russian. Assignment is the third. Analyze groups of words and sentences.

1. Specify ways of grammatical communication of words.

a) Write down the third paragraph of the text and underline articles, prepositions, conjunctions and auxiliary verbs.

b) Explain the grammatical function of the underlined words.

2. Identify the personal form of the verb in the sentence:

a) Write down the following sentence ....

b) Underline in this sentence the personal form of the verb and convey the exact content of this sentence.

Task four. Check the accuracy of reading.

1. Set the value of the word-combinations of the 1 st paragraph of the text.

a) Read the 1st paragraph of the text.

b) What are the equivalents in Russian for the following word combinations ....

2. Pass the contents of the read.

a) What are the ways of communication of independent words and the meaning of these combinations in Russian ....

Task four. Check the accuracy of reading.

Pass the contents of the second paragraph in Russian in a written form.

Task five. Correctly read the text aloud.

1. Follow the reading of the 2 nd paragraph.

2. Prepare to read the second paragraph aloud.

Task six. Prepare an outline of the content of the text. 
1. Write out key sentences from each semantic part of the text and simplify them so that they become paragraphs of the plan to the text.

2. Write down the main points of the plan, corresponding to the semantic parts of the text.

Task seven. Outline the content of the text in English ....

1. Generalizing speech tasks to the text.

Assignment is the first. Observing the sequence of work on the text, specify the order of tasks. Check the answer by key

1) Check the accuracy of reading. 2) Prepare for the transmission of the content of the text. 3) Read the general content of the text. 4) Analyze groups of words and sentences. 5) Read the text aloud.

6) Describe the content of the text. 7) Perform an analysis of the lexical composition.

Task two. Read the general content of the text.

Assignment is the third. To check the meaning of words, indicate which letter (a, b, c) is given the English word corresponding to the Russian equivalent. Check the answer by key.

Task four. Indicate which sentence in Russian in its content exactly corresponds to the sentence in English.

Task five. Arrange points of the plan in accordance with the content of the text.

\section{Conclusions}

Thus, the use of the organization of methodological support for learning through the prism of such activities as reading and its proper organization has had a significant impact on the effectiveness of student learning. Students were offered different types of reading, depending on the task being solved in a specific reading situation; we were offered introductory, in-depth and translated-abstract reading. For each situation (the type of reading) is designed its own set of training assignments. Such organization of educational activity in English language classes allows considering the process of formation of communicative competence in a foreign language as an integral part of the formation of the communicative personality of the future specialist in the process of vocational training. And the correct methodological organization of the process of forming this competence on the basis of the application of various types of reading actualizes the desire, motivation of students for personal and professional development and self-improvement of students of technical specialties.

\section{References}

. Alsu Linarovna Mirzagitova, Alksandr Gennadievich Ilin, Aygul Zufarovna Ibatova (2017). The role of knowledge and pedagogical communication in modern society. Revista QUID (Special Issue), 1613-1617. 
2. Igorevna, Kuzmenko Valentina; Gennadievich, Ilyin Alexander; Ibatova Zufarovna, Aygul (2017). Levels of linguistic self-education among students of non-linguistic specialties. Revista QUID (Special Issue), 865-869.

3. Kosenok Sergei Mikhailovich, Rasskazov Philip Dementievich, Stavruk Marina leksandrovna, Muller Olga Yuryevna, Ilyashenko Lubov Kiryalovna (July 2017). The implementation of the idea of free pedagogy in the modern education. Modern Journal of Language Teaching Methods. Volume 7, Issue 7, Pages 87-98.

4. Belova, S.V. Pedagogy and dialogue / S. V. Belova. - M., 2006. - P. 18-37.

5. Dyachenko, M. I. Brief psychological dictionary: Personality education, self-education, profession / MI Dyachenko, LA Kandybovich. - Mn .: "Halton", 1998. - 399 p.

6. Kalyanova, L.M. Work program on the discipline "Foreign Language", publishing house Tyumen Industrial University, 2016.

7. Kodzhaspirova, G.M. Pedagogical dictionary: For students of higher education. training. institutions / GM Kodzhaspirova, A. Yu. Kodzhaspirov. - 2 nd ed., Sr. - Moscow: Publishing house "Academia", 2005. - 176 p.

8. Konysheva, A.V. Modern methods of teaching English / AV Konysheva. - 3rd ed. - Mn .: "TetraSystems", 2005.$176 \mathrm{p}$.

9. Petrovsky, A.V. Issues of History and Psychology: Izbr. works. - M .: Pedagogy, 1984. - 271p.

10. Serikov, V.V. Training as a kind of pedagogical activity: Textbook. allowance for stud. supreme. training. institutions / V. Serikov; Ed. V.A. Slastenina, I. A. Kolesnikova. - Moscow: Izd. Center "Academy", 2008. - 256 p.

11. Philosophical Encyclopedic Dictionary / Ch. edition: LF Il'ichev, PN Fedoseev, SM Kovalev, G.V. Panov. Moscow: Soviet Encyclopedia, 1983. - 840 p.

12. Philosophical Encyclopedic Dictionary / Ed. - comp. E. F. Gubsky, G. V. Korablev. - Moscow: Publishing house "Infra-M". 2006. - 576 p. 